\title{
GCU
}

Glasgow Caledonian

University

University for the Common Good

\section{Reliability modelling and analysis of a single machine subsystem of a cable plant}

Taj, Syed Zegham; Rizwan, S. ; Alkali, B.M.; Harrison, D.K.; Taneja , G.

Published in:

2017 7th International Conference on Modeling, Simulation, and Applied Optimization, ICMSAO 2017

DOI:

10.1109/ICMSAO.2017.7934917

Publication date:

2017

Document Version

Author accepted manuscript

Link to publication in ResearchOnline

Citation for published version (Harvard):

Taj, SZ, Rizwan, S, Alkali, BM, Harrison, DK \& Taneja, G 2017, Reliability modelling and analysis of a single machine subsystem of a cable plant. in 2017 7th International Conference on Modeling, Simulation, and Applied Optimization, ICMSAO 2017. IEEE. https://doi.org/10.1109/ICMSAO.2017.7934917

\section{General rights}

Copyright and moral rights for the publications made accessible in the public portal are retained by the authors and/or other copyright owners and it is a condition of accessing publications that users recognise and abide by the legal requirements associated with these rights.

Take down policy

If you believe that this document breaches copyright please view our takedown policy at https://edshare.gcu.ac.uk/id/eprint/5179 for details of how to contact us. 


\title{
Reliability Modelling and Analysis of a Single Machine Subsystem of a Cable Plant
}

\author{
Taj S Z $Z^{1}$, Rizwan $\mathrm{S} \mathrm{M}^{2}$, Alkali B $\mathrm{M}^{3}$, Harrison $\mathrm{D} \mathrm{K}^{4}$ and Taneja $\mathrm{G}^{5}$ \\ ${ }^{1 \& 2}$ Department of Mathematics \& Statistics, Caledonian College of Engineering, Seeb, Oman \\ ${ }^{3 \& 4}$ Department of Mechanical Engineering, Glasgow Caledonian University, Glasgow, Scotland, UK \\ ${ }^{5}$ Department of Mathematics, Maharshi Dayanand University, Rohtak, Haryana, India
}

\begin{abstract}
This paper presents a real case analysis of a single machine subsystem of a cable plant using reliability modelling. Real maintenance data of a cable plant are collected for this purpose. Three types of maintenance are noted for the subsystem: repair, preventive maintenance random (PMR) and preventive maintenance scheduled (PMS). The subsystem is repaired upon failure, while preventive maintenance $(P M)$ is carried out at random and scheduled basis. Optimum reliability indices such as mean time to subsystem failure (MTSF), availability of the subsystem, expected busy period of the repairman and expected number of subsystem repairs are obtained. Analysis is done using semi Markov processes and regenerative point techniques.
\end{abstract}

Keywords - reliability, semi Markov process, regenerative point technique, failure, repair, preventive maintenance.

\section{NOTATIONS}

Operative state

Down state

Failed state

Operative

Down for PMS

Down for PMR

Failed, under repair

Fr

$\alpha_{1}$

$\alpha_{2}$

$\beta$

Estimated value rate of requirement of PMS

Estimated value rate of requirement of PMR

pdf of PMS times

$\mathrm{f}_{2}(\mathrm{t}) \quad$ pdf of PMR times

$\mathrm{g}(\mathrm{t}) \quad$ pdf of repair times

$\omega_{1} \quad$ Estimated value rate of performing PMS

$\omega_{2} \quad$ Estimated value of rate of performing PMR

$\gamma \quad$ Estimated value of repair rate

$Q_{i j} \quad$ cdf from state $i$ to state $j$

$\mathrm{q}_{\mathrm{ij}} \quad$ pdf from state $\mathrm{i}$ to state $\mathrm{j}$

cdf Cumulative distribution function

pdf Probability density function
*/LT Laplace transform

**/LST Laplace Stieltje's transform

(C) Laplace convolution

S Laplace Stieltje's convolution

$\mathrm{A}_{0} \quad$ Availability of the subsystem

$\mathrm{B}_{0} \quad$ Expected busy period of the repairman

$\mathrm{R}_{0} \quad$ Expected number of subsystem repairs

\section{INTRODUCTION}

In this fast developing world, demand for cables is consistently increasing as they play a vital role in infrastructure enhancement. Moreover, cable plants involve a series of complex procedures carried out using highly sophisticated subsystems. Hence in order to fulfill the demands of the market, these subsystems must be kept in operation without failure. Many researchers have analysed various industrial systems with different operating conditions and assumptions using reliability modelling. Mathew, Rizwan, Majumder and Ramachandran [1] discussed reliability modelling and analysis of a two unit continuous casting plant. Padmavathi, Rizwan, Anita and Taneja [2] carried out reliability analysis of an evaporator of a desalination plant with online repair and emergency shutdowns. Sanjay and Suresh [3] performed stochastic analysis of a reliability model of one-unit system with post inspection, post repair, preventive maintenance and replacement. Reetu and Gulshan [4] wrote on stochastic analysis of a two unit cold standby system wherein both units may become operative depending upon the demand. Rizwan, Padmavathi and Taneja [5] carried out performance analysis of a desalination plant as a single unit with mandatory shutdown during winter. Recently, Upasana and Jaswinder [6] performed cost benefit analysis of a compressor standby system with preference of service, repair and replacement given to recently failed unit. An interesting situation is noted at the cable plant through reported maintenance data where PM is carried out at random and on scheduled basis whereas the repair upon failure. 
In order to understand the subsystem behaviour which contributes to overall performance of the cable plant, the following reliability indices are obtained using semi Markov processes and regenerative point techniques:

- MTSF

- Availability of the subsystem

- Expected busy period of the repairman

- $\quad$ Expected number of subsystem repairs

This paper thus discuss the reliability theory in terms of real case analysis. Seven years maintenance data of a cable plant currently operational in Oman are collected for the analysis. Maintenance data of the cable plant depicts three types of maintenance for the subsystem i.e. repair, PMR and PMS. These maintenance situations are considered in the present reliability modelling. Table1 gives the real values of rate of repair/failure and rate of performing/requirement of PM estimated for the subsystem from the maintenance data of the cable plant. These values are used to carry out the analysis. Possible transition states $0,1,2$ and 3 of the subsystem are shown in Figure1. In state $0(\mathrm{Op})$ the subsystem is operative. In state 1 (Dpms) the subsystem is down for PMS and in state 2 (Dpmr) the subsystem down for PMR. State 3 (Fr) is the failed state, here the subsystem is under repair. The subsystem regenerates and works as new after PMS, PMR or repair is carried out. Failure rate is taken as exponential wheras repair/ PM rates could be arbitrary.

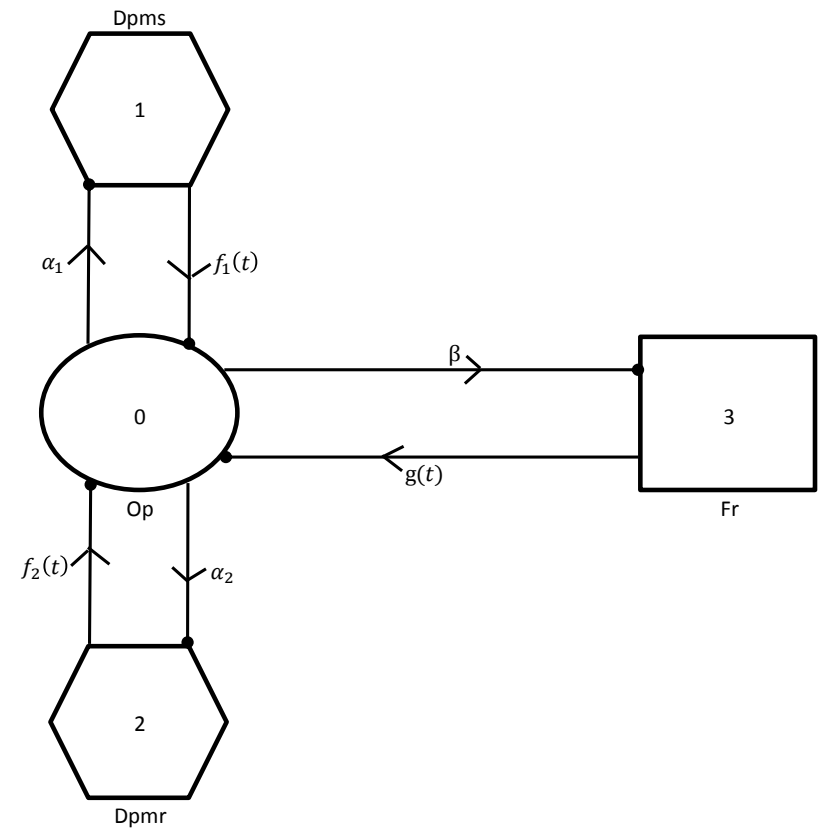

Figure1: Transition states of the subsystem

\begin{tabular}{|c|c|c|}
\hline S. No. & RATE & VALUE \\
\hline 1 & $\begin{array}{l}\text { failure rate } \\
\beta=\frac{\text { no. of times repair done }}{\text { total time between repair }}\end{array}$ & 0.0076100304 \\
\hline 2 & $\begin{array}{l}\text { rate of requirement of PMS } \\
\alpha_{1}=\frac{\text { no. of times PMS done }}{\text { total time between PMS }}\end{array}$ & 0.0005136106 \\
\hline 3 & $\begin{array}{l}\text { rate of requirement of PMR } \\
\alpha_{2}=\frac{\text { no. of times PMR done }}{\text { total time between PMR }}\end{array}$ & 0.0024560337 \\
\hline 4 & $\begin{array}{l}\text { repair rate } \\
\gamma=\frac{\text { no. of times repair done }}{\text { total time for repair }}\end{array}$ & 0.1695486189 \\
\hline 5 & $\begin{array}{l}\text { rate of performing PMS } \\
\omega_{1}=\frac{\text { no. of times PMS done }}{\text { total time for PMS }}\end{array}$ & 0.0455212922 \\
\hline 6 & $\begin{array}{l}\text { rate of performing PMR } \\
\omega_{2}=\frac{\text { no. of times PMR done }}{\text { total time for PMR }}\end{array}$ & 0.8883693746 \\
\hline
\end{tabular}

Table1: Values of rates for the subsystem

\section{TRANSITON PROBABILITIES AND MEAN SOJOURN TIMES}

Possible transition states of the subsystem are shown in Figure1. States 0, 1, 2 and 3 are the regenerative states from where the subsystem regenerates after PM or repair as necessary.

Transition probabilities from state $\mathrm{i}$ to state $\mathrm{j}, \mathrm{q}_{\mathrm{ij}}(\mathrm{t})$ are given by equations (1-6)

$$
\begin{aligned}
& \mathrm{q}_{01}(\mathrm{t})=\alpha_{1} \mathrm{e}^{-\left(\alpha_{1}+\alpha_{2}+\beta\right) \mathrm{t}} \\
& \mathrm{q}_{02}(\mathrm{t})=\alpha_{2} \mathrm{e}^{-\left(\alpha_{1}+\alpha_{2}+\beta\right) \mathrm{t}} \\
& \mathrm{q}_{03}(\mathrm{t})=\beta \mathrm{e}^{-\left(\alpha_{1}+\alpha_{2}+\beta\right) \mathrm{t}} \\
& \mathrm{q}_{10}(\mathrm{t})=\mathrm{f}_{1}(\mathrm{t}) \\
& \mathrm{q}_{20}(\mathrm{t})=\mathrm{f}_{2}(\mathrm{t}) \\
& \mathrm{q}_{30}(\mathrm{t})=\mathrm{g}(\mathrm{t})
\end{aligned}
$$

Using the definition [1] of nonzero elements $\mathrm{p}_{\mathrm{ij}}$, we get equations (7-12)

$$
\begin{aligned}
& \mathrm{p}_{01}=\frac{\alpha_{1}}{\alpha_{1}+\alpha_{2}+\beta} \\
& \mathrm{p}_{02}=\frac{\alpha_{2}}{\alpha_{1}+\alpha_{2}+\beta} \\
& \mathrm{p}_{03}=\frac{\beta}{\alpha_{1}+\alpha_{2}+\beta} \\
& \mathrm{p}_{10}=\mathrm{f}_{1}{ }^{*}(0) \\
& \mathrm{p}_{20}=\mathrm{f}_{2}{ }^{*}(0) \\
& \mathrm{p}_{30}=\mathrm{g}^{*}(0)
\end{aligned}
$$

Equations (13-16) can be easily verified

$\mathrm{p}_{01}+\mathrm{p}_{02}+\mathrm{p}_{03}=1$

$\mathrm{p}_{10}=1$

$\mathrm{p}_{20}=1$

$\mathrm{p}_{30}=1$ 
Using the definition [1] of mean sojourn time $\mu_{\mathrm{i}}$, we get equations (17-20)

$$
\begin{aligned}
& \mu_{0}=\frac{1}{\alpha_{1}+\alpha_{2}+\beta} \\
& \mu_{1}=\int_{0}^{\infty} \mathrm{tf}_{1}(\mathrm{t}) \mathrm{dt} \\
& \mu_{2}=\int_{0}^{\infty} \mathrm{tf}_{2}(\mathrm{t}) \mathrm{dt} \\
& \mu_{3}=\int_{0}^{\infty} \operatorname{tg}(\mathrm{t}) \mathrm{dt}
\end{aligned}
$$

Using equations (17-20) and the definition [1] of unconditional mean time $\mathrm{m}_{\mathrm{ij}}$, we get equations (21-24)

$\mathrm{m}_{01}+\mathrm{m}_{02}+\mathrm{m}_{02}=\mu_{0}$

$\mathrm{m}_{10}=\mu_{1}$

$\mathrm{m}_{20}=\mu_{2}$

$\mathrm{m}_{30}=\mu_{3}$

\section{A. Mean time to subsystem failure}

\section{RELIABILITY ANALYSIS}

Consider the failed state 3 of the subsystem as an absorbing state. Using simple probabilistic arguments and the definition [1] of $\phi_{\mathrm{i}}(\mathrm{t})$, we get equations (25-27)

$$
\begin{aligned}
& \phi_{0}(\mathrm{t})=\mathrm{Q}_{01}(\mathrm{t}) \boldsymbol{S} \phi_{1}(\mathrm{t})+\mathrm{Q}_{02}(\mathrm{t}) \boldsymbol{S} \phi_{2}(\mathrm{t})+\mathrm{Q}_{03}(\mathrm{t}) \\
& \phi_{1}(\mathrm{t})=\mathrm{Q}_{10}(\mathrm{t}) \boldsymbol{S} \phi_{0}(\mathrm{t}) \\
& \phi_{2}(\mathrm{t})=\mathrm{Q}_{20}(\mathrm{t}) \boldsymbol{S} \phi_{0}(\mathrm{t})
\end{aligned}
$$

Taking Laplace Stieltjes transform (LST) of equations (25-27) and solving for $\phi_{0}{ }^{* *}(\mathrm{~s})$, we obtain equation (28)

$$
\phi_{0}^{* *}(\mathrm{~s})=\frac{\mathrm{N}(\mathrm{s})}{\mathrm{D}(\mathrm{s})}
$$

MTSF when the subsystem started at the beginning of state 0 is given by equation (29)

MTSF $=\lim _{\mathrm{s} \rightarrow 0} \frac{1-\phi_{0}{ }^{* *}(\mathrm{~s})}{\mathrm{s}}=\frac{\mathrm{N}}{\mathrm{D}}$

where

$\mathrm{N}=\mu_{0}+\mathrm{p}_{01} \mu_{1}+\mathrm{p}_{02} \mu_{2}$

$\mathrm{D}=\mathrm{p}_{03}$

\section{B. Availability of the subsystem}

Using simple probabilistic arguments and the definition [1] of $A_{i}(t)$, we get equations (30-33)

$$
\begin{aligned}
& A_{0}(t)= M_{0}(t)+q_{01}(t) \subset A_{1}(t)+q_{02}(t) C A_{2}(t)+ \\
& q_{03}(t) \subset A_{3}(t) \\
& A_{1}(t)= q_{10}(t) \subset A_{0}(t) \\
& A_{2}(t)= q_{20}(t) \subset A_{0}(t) \\
& A_{3}(t)= q_{30}(t) \subset A_{0}(t) \\
& \text { here, } M_{0}(t)=e^{-\left(\alpha_{1}+\alpha_{2}+\beta\right) t}
\end{aligned}
$$

Taking Laplace transform (LT) of equations (30-33) and solving for $\mathrm{A}_{0}{ }^{*}(\mathrm{~s})$, we get equation (35)

$$
A_{0}^{*}(s)=\frac{N_{1}(s)}{D_{1}(s)}
$$

In steady state, availability of the subsystem is given by equation (36)

$A_{0}=\lim _{s \rightarrow 0} s_{0}^{*}(s)=\frac{N_{1}}{D_{1}}$

where

$\mathrm{N}_{1}=\mu_{0}$

$\mathrm{D}_{1}=\mu_{0}+\mathrm{p}_{01} \mu_{1}+\mathrm{p}_{02} \mu_{2}+\mathrm{p}_{03} \mu_{3}$

\section{Expected busy period of the repairman}

Using simple probabilistic arguments and the definition [1] of $B_{i}(t)$, we get equations (37-40)

$\mathrm{B}_{0}(\mathrm{t})=\mathrm{q}_{01}(\mathrm{t}) \subset \mathrm{B}_{1}(\mathrm{t})+\mathrm{q}_{02}(\mathrm{t}) \subset \mathrm{B}_{2}(\mathrm{t})+\mathrm{q}_{03}(\mathrm{t}) \mathbb{C} \mathrm{B}_{3}(\mathrm{t})$

$\mathrm{B}_{1}(\mathrm{t})=\mathrm{q}_{10}(\mathrm{t}) \subset \mathrm{B}_{0}(\mathrm{t})$

$\mathrm{B}_{2}(\mathrm{t})=\mathrm{q}_{20}(\mathrm{t}) \subset \mathrm{B}_{0}(\mathrm{t})$

$\mathrm{B}_{3}(\mathrm{t})=\mathrm{W}_{3}(\mathrm{t})+\mathrm{q}_{30}(\mathrm{t}) \subset \mathrm{B}_{0}(\mathrm{t})$

here, $\mathrm{W}_{3}(\mathrm{t})=\overline{\mathrm{G}(\mathrm{t})}$

Taking LT of equations (37-40) and solving for $\mathrm{B}_{0}{ }^{*}(\mathrm{~s})$, we obtain equation (42)

$\mathrm{B}_{0}^{*}(\mathrm{~s})=\frac{\mathrm{N}_{2}(\mathrm{~s})}{\mathrm{D}_{1}(\mathrm{~s})}$

In steady state, expected busy period of the repairman is given by equation (43)

$\mathrm{B}_{0}=\lim _{\mathrm{s} \rightarrow 0} \mathrm{sB}_{0}^{*}(\mathrm{~s})=\frac{\mathrm{N}_{2}}{\mathrm{D}_{1}}$

where

$\mathrm{N}_{2}=\mathrm{p}_{03} \mu_{3}$

\section{Expected number of subsystem repairs}

Using simple probabilistic arguments and the definition [1] of $R_{i}(t)$, we get equations (44-47)

$\mathrm{R}_{0}(\mathrm{t})=\mathrm{Q}_{01}(\mathrm{t}) \boldsymbol{S} \mathrm{R}_{1}(\mathrm{t})+\mathrm{Q}_{02}(\mathrm{t}) \boldsymbol{S} \mathrm{R}_{2}(\mathrm{t})+\mathrm{Q}_{03}(\mathrm{t}) \boldsymbol{S} \mathrm{R}_{3}(\mathrm{t})$

$\mathrm{R}_{1}(\mathrm{t})=\mathrm{Q}_{10}(\mathrm{t}) S \mathrm{R}_{0}(\mathrm{t})$

$\mathrm{R}_{2}(\mathrm{t})=\mathrm{Q}_{20}(\mathrm{t}) S \mathrm{R}_{0}(\mathrm{t})$

$\mathrm{R}_{3}(\mathrm{t})=\mathrm{Q}_{30}(\mathrm{t}) \mathbf{S}\left\{1+\mathrm{R}_{0}(\mathrm{t})\right\}$

Taking LST of equations (44-47) and solving for $\mathrm{R}_{0}{ }^{* *}(\mathrm{~s})$, we get equation (48)

$\mathrm{R}_{0}{ }^{* *}(\mathrm{~s})=\frac{\mathrm{N}_{3}(\mathrm{~s})}{\mathrm{D}_{1}(\mathrm{~s})}$

In steady state, expected number of subsystem repairs per unit time is given by equation (49)

$\mathrm{R}_{0}=\lim _{\mathrm{s} \rightarrow 0} \mathrm{~s} \mathrm{R}_{0}^{* *}(\mathrm{~s})=\frac{\mathrm{N}_{3}}{\mathrm{D}_{1}}$

where

$\mathrm{N}_{3}=\mathrm{p}_{03}$

\section{PARTICULAR CASE}

Let the failure times and other times as well follow exponential distribution i.e.

$$
\begin{aligned}
& g(t)=\gamma e^{-\gamma t} \\
& f_{1}(t)=\omega_{1} e^{-\omega_{1} t} \\
& f_{2}(t)=\omega_{2} e^{-\omega_{2} t}
\end{aligned}
$$


Then, using the values of rates for the subsystem given in Table1 and equations (1-52), following reliability indices can be obtained

MTSF: 133.25144113 hours

Availability of the subsystem: 0.94434808

Expected busy period of the repairman: 0.04238618

Expected number of subsystem repairs: 0.00718652/hour

\section{CONCLUSION}

Reliability indices for a single machine subsystem of a cable plant are obtained in terms of mean time to subsystem failure, availability of the subsystem, expected busy period of the repairman and expected number of subsystem repairs. In order to achieve improved results of these indices, some of the maintenance practices and their frequency could further be reviewed. The analysis could be extended for more types of failures and online repairs possibility.

\section{References}

[1] A.G. Mathew, S.M. Rizwan, M.C. Majumder and K.P. Ramachandran, "Reliability modelling and analysis of a two unit continuous casting plant", Journal of the Franklin Institute, vol. 348, pp. 1488-1505, 2011.

[2] N. Padmavathi, S.M. Rizwan, Anita Pal and G. Taneja, "Reliability analysis of an evaporator of a desalination plant with online repair and emergency shutdowns", Aryabhatta Journal of Mathematics and Informatics, vol. 4, no. 1, pp. 1-12, 2012.

[3] Sanjay Gupta and Suresh Kumar Gupta, "Stochastic analysis of a reliability model of one-unit system with post inspection, post repair, preventive maintenance and replacement", International Journal of Mechanical Engineering and Robotics Research, vol. 2, no. 2, pp. 178$188,2013$.

[4] Reetu Malhotra and Gulshan Taneja, "Stochastic analysis of a two-unit cold standby system whereinboth units may become operative depending upon the demand", Journal of Quality and Reliability Engineering, pp. 1-13, 2014.

[5] S.M. Rizwan, N. Padmavathi and G. Taneja, "Performance analysis of a desalination plant as a single unit with mandatory shutdown during winter", Aryabhatta Journal of Mathematics and Informatics, vol. 7, no. 1, pp. 195-202, 2015.

[6] Upasana Sharma and Jaswinder Kaur, "Cost benefit analysis of a compressor standby system with preference of service, repair and replacement is given to recently failed unit", International Journal of Mathematics Trends and Technology, vol. 30, no. 2, 2016. 